\title{
EM TORNO DA PROBLEMÁTICA DE DEFINIR RELIGIÃO ${ }^{1}$
}

\author{
Adilson Koslowski (UFS) ${ }^{2}$
}

kadilson@ibest.com.br

Resumo: Este artigo tem a finalidade de analisar a problemática de definir de forma explícita e classificativa o conceito de religião. Concordamos com os critérios de precisão extensional, neutralidade, fenomenologia e não circularidade estabelecidos por Mark Owen Webb (2009) como adequados a uma boa definição filosófica de religião. Contudo, todas as tentativas de estabelecer uma definição explícita que satisfaça tais critérios não tiveram êxito. Propomos uma definição de religião menos exigente, sustentada por Morris Weitz (1956) para a literatura e mutatis mutandis aplicada ao conceito de religião. Igualmente, a definição pode ser refinada pela teoria prototípica como foi desenvolvida por Benson Saler (2000).

Palavras-chave: definição; religião; conceito.

\section{CONSIDERAÇÕES INICIAIS}

Nosso objetivo aqui é encontrar uma definição filosoficamente adequada de religião. É comum, nos livros de filosofia analítica da religião, os autores passarem muito rapidamente pelo problema da definição ou apenas pressuporem um conceito que abranja fundamentalmente o judaísmo e o cristianismo. Assim, religião envolveria um sistema de crenças e práticas primeiramente centradas em torno de uma realidade transcendente pessoal, que providencia o

\footnotetext{
${ }^{1}$ Recebido: 25-10-2012/Aprovado: 29-05-2013/Publicado on-line: 29-09-2013.

${ }^{2}$ Adilson Koslowski é Professor Adjunto da Universidade Federal do Sergipe, São Cristóvão, SE, Brasil.
} 
significado último e o propósito da vida. Aparentemente parece fácil saber o que é religião. Mas, se olharmos como as pessoas usam o termo, veremos que existe uma variação enorme. Um cristão, um taoísta, um ateu, um comunista, uma feminista e até um vegetariano praticam alguma espécie de religião pelas suas arraigadas convicções. Por exemplo, um torcedor "fanático" por futebol considera esse esporte seu deus, que o absorve física e espiritualmente. $\mathrm{O}$ futebol para ele é sua religião, que o redime e o compensa de todas as agruras da vida sofredora.

Era convicção, por parte de muitos na década de 1960, que a religião desapareceria ou ficaria restrita a pequenos grupos. Vejamos as observações do renomado antropólogo Anthony F. C. Wallace (1966, 25 apud STARK e BAINBRIDGE 2008, 16):

[...] o futuro evolucionário da religião é a extinção. A crença em seres e forças sobrenaturais que afetam a natureza sem obedecer a leis naturais vai se desgastar e se tornar apenas uma memória histórica interessante. Com efeito, este evento não deve acontecer nos próximos cem anos, e provavelmente sempre haverá indivíduos, ou mesmo pequenos grupos de culto, que responderão à alucinação, ao transe e à obsessão por uma interpretação sobrenatural. Mas, como característica cultural, a crença em forças sobrenaturais está condenada à morte, no mundo todo, como resultado da crescente adequação à difusão do conhecimento científico e da conclusão, pelas crenças seculares, de que a crença no sobrenatural não é necessária para a humanidade, esta é uma questão irrelevante para a predição; o processo é inevitável.

Contudo, essa ideia não era verdadeira e a religião tornou-se nos últimos anos um fenômeno em expansão. A própria filosofia da religião, pelo menos a de tradição analítica, teve um grande florescimento. Exibe entre seus pensadores William Alston, Alvin Plantinga, Nicholas Woltertorff, Richard Swinburne, John Hick. Porém, o con- 
ceito de religião não recebeu muito interesse entre os filósofos dessa tradição, muito mais dispostos em resgatar os clássicos problemas da filosofia da religião, como o da existência de Deus, a coerência das propriedades divinas, o problema do mal.

\section{AlguMAS CONSIDERAÇÕES A RESPEITO DA DEFINIÇÃO}

Segundo Hegenberg (1974) e Murcho (2006), as definições podem ser classificadas como nominais e reais. As definições nominais são usadas para introduzir convenções linguísticas e são de três tipos: lexicais, estipulativas e de precisão. As lexicais são aquelas que já estão em uso e são encontradas nos dicionários; as estipulativas criam novos termos ou usam os já existentes com outro significado; as de precisão tornam o discurso mais preciso, como, no $\mathrm{Di}$ reito, a distinção entre roubar e furtar. A seguir faremos uma análise nominal do termo religião mostrando como esse termo foi estabelecido linguisticamente pela influência de Cícero e Lactâncio.

Continuando, as definições reais querem estabelecer relações entre duas entidades - e não são simples convenções - a saber, entre o definiendum (o que se quer definir) e a definiens (a que o define). Por exemplo, a espécie natural ouro pode ser definida como o elemento cujo peso atômico é 79 . Veremos que algumas definições propostas para o conceito de religião tendem a aceitar sua definição como uma espécie natural. Porém, ultimamente surgiram propostas para definir a religião como um artifício metodológico ou construto introduzido pelos cientistas como uma necessidade metodológica para a investigação.

Segundo Murcho (2006), as definições podem ser explí- 
citas, isto é, buscam condições necessárias e suficientes. Por exemplo, o número dois pode ser definido como par (condição necessária, mas evidentemente não suficiente) e primo (propriedade necessária, mas igualmente não suficiente), contudo, juntas, as duas propriedades estabelecem a necessidade e a suficiência de uma definição explícita. As definições explícitas podem ser subdivididas em três tipos: analíticas, essencialistas e extensionais. As analíticas nos oferecem sinônimos - por exemplo, solteiro é um homem não casado. As essencialistas definem o objeto por meio de propriedades metafísicas. Assim, a definição de ouro dada anteriormente é verdadeira em todos os mundos possíveis. Por fim, as definições extensionais definem pela extensão do termo. Por exemplo, "presidente do Brasil do ano de 2012" tem apenas um objeto que cai sob essa extensão, no caso, Dilma Rousseff. Além das definições explícitas temos as implícitas. Essas definições não necessitam que sejam dadas condições necessárias e suficientes. São de dois tipos: ostensivas e contextuais. Ostensão é mostrar algo. Portanto, definir um pato é mostrar, por exemplo, com o dedo, o que é um pato. Segundo Hegenberg (1974), as contextuais são as definições cujo definiens não é definido sozinho, mas num contexto linguístico, por exemplo, irmão. É melhor defini-lo, como x é irmão de y, assim, x é irmão de y, é um indivíduo masculino que tem os mesmos pais de y. Em lógica, podemos usar os termos primitivos e definir contextualmente para introduzir novos termos. Assim, "é necessário que p" (abreviatura) possa ser definido como "não é possível que não seja o caso que p".

Linda Zagzesbki (2008, 164-165) nos oferece uma lista de critérios úteis quando analisamos ou buscamos definir algo. Em suas palavras: 
[...] uma definição não deve ser ad hoc, não deve ser negativa, quando pode ser positiva, deve ser breve, não deve ser circular, deve utilizar apenas conceitos que sejam menos obscuros que o conceito a ser definido, e muitos outros... uma definição deveria dizer-nos algo que ainda não sabíamos. Queremos uma definição por não conseguir apreender de forma clara o conceito a ser definido. Uma definição circular não faz isso, já que usa o conceito a ser definido na definiens, e uma definição que usa outros conceitos que também precisam de definição com o definiendum também não consegue. Definições negativas falham de uma forma mais sutil. Elas nos dizem o que algo não é, não o que é.

Mais especificamente, concordamos e seguiremos os critérios estabelecidos por Mark Owen Webb (2009) para uma definição explícita e filosófica de religião. São eles: precisão extensional, neutralidade, fenomenologia e não circularidade.

\section{DEFINIÇÃO NOMINAL DE RELIGIÃO}

Nas definições nominais de religião sigo as ideias e argumentos de Klaus Hock (2010). Uma das coisas que podemos reconhecer é o conceito de religião ser uma invenção ocidental latina que tem sua origem remota no latim. A fonte latina é o senador e filósofo romano Cícero (106-43 a.C.). Encontramos a referência em seu livro De natura deorum (Sobre a natureza dos deuses). A palavra latina religio é definida como cultus deorum, isto é, culto, cultivo, adoração. É central o elemento de comportamento correto de culto. $\mathrm{O}$ termo é o oposto de relegere, negligenciar. $\mathrm{O}$ acento está na prática ritualista (ortopráxis), não na doutrina correta (ortodoxia). Porém, existe outra fonte. Um escrito cristão, Lactâncio (séc. III/IV), define religião como vindo do verbo latino religare, isto é, ligar, amarrar de novo. Essa definição será a adotada pelo filósofo e teólogo cristão Agostinho de 
Hipona (354-430), cuja influência fará com que religião signifique majoritariamente ligar de volta a alma que se afastou de Deus. Hock (2010) defende que o conceito de Cícero é o mais primitivo. Primeiro porque o contrário de religio é superticio, isto é, atuação errada. Outro argumento é de que no próprio cristianismo religioso (religiosi) monges e freiras estão num estado religioso que é o da atuação cúltica correta (status perfectionis).

O termo "religião" vai ganhar outros significados na história ocidental. No humanismo (século XIV), "religião" tem o sentido de "fé comum, confissão". Na mesma época, a Reforma transforma o conceito religião em um conceito teologicamente negativo. "Religião" é sinônimo de "magia e superstição". O conceito é ligado aos cultos idólatras e pagãos, fazendo referência crítica e direta aos cultos do catolicismo católico romano. O termo "religião" vai sofrer outra grande transformação no iluminismo (século XVIII). Religião ganha uma dimensão universal e ideal como uma eidos platônica. As religiões com " $r$ " minúsculo participam da Religião, com "R" maiúsculo, mesmo que de um modo imperfeito. A Religião foi infelizmente perdida e deve ser recuperada, como em, por exemplo, Natã, o sábio, de Gothold E. Lessing (1729-1781). Outras vezes, a religião é descrita como uma realidade histórica e evolutiva, de uma realidade primitiva e elementar e se transforma na verdadeira Religião, identificada com o cristianismo.

Hock (2010) argumenta que o conceito religião, de fato, é um produto do Ocidente latino. O centro de sua argumentação é que não existe um conceito correspondente, seja nas línguas grega, árabe, hindi, japonês ou chinês. Em grego temos três termos com semelhanças com o conceito ocidental. O termo eusébeia - temor/respeito - não apenas 
aplicado aos deuses, mas aos seres humanos e objetos de valor; o termo latréia - serviço cúltico, serviço prestado; e threskéia - ato de cumprir um mandamento. O conceito grego é mais amplo que o latino. No oriente, os problemas são piores. No árabe, dîn - acertar algo - isto é, aquilo que se deve a Deus, em suma, equivale a deveres de religião. No sânscrito, dharma significa "carregar, segurar" e têm vários outros significados. Os deuses seguram e mantêm unido o cosmos, colocam ordem. Em páli, dhamma relaciona-se com o caminho de Buda, a senda óctupla, não uma doutrina, mas a ordem das coisas. Contudo, têm vários outros significados, paradoxalmente, de doutrina também. Por fim, nas religiões africanas e oceânicas não há nada para comparar.

Segundo Hock (2010), a religião não existe. O que existe é um construto teórico por parte dos estudiosos da religião que tem uma necessidade de um objeto material e de reconhecimento para seu trabalho. O conceito de religião é uma abstração da realidade cultural para fins acadêmicos. Semelhante tese é defendida, mesmo que por estratégias diferentes, pelo historiador da religião Jonathan Z. Smith, em seu livro Imagining religion (1988). Segundo Smith, não existem fatos para a religião (there is no data for religion), ela é um construto do homem ocidental, enquanto para a quase a totalidade dos homens o intercâmbio com os deuses era parte constante de suas vidas. $\mathrm{O}$ homem ocidental isolou alguns traços da vida humana e chamou de religião. A religião não é algo que existe independente da academia. É um conceito útil advindo da imaginação dos cientistas da religião em suas comparações e generalizações. Teses semelhantes também são defendidas por Wilfred C. Smith, em The meaning and end of religion (1964), e Tomoko Masuzawa, em The invention of world religions (2005). Mais radicalmente, 
Timothy Fitzgerald, em seu livro The ideology and religious studies (2003), defende a simples extirpação do conceito de religião sustentando que o conceito é uma construção ideológica ocidental e seus usos são politicamente negativos. Em relação a essa problemática da origem do conceito, sugerimos que seja resolvida pelas ciências empíricas da filologia, história, arqueologia e antropologia, e não pela filosofia.

\section{A BUSCA DE DEFINIÇÕES EXPLÍCITAS DE RELIGIÃO}

A busca de uma definição explícita de religião é uma área bastante desenvolvida em sociologia e principalmente em antropologia. Existe um diálogo fecundo entre essas ciências sociais e a filosofia. Antropólogos e sociólogos tipificam as definições de religião em substantivas e funcionais. As definições substantivas são aquelas em que a religião é definida em termos de entidades sobrenaturais, sendo, pois, crença em Deus, crenças em seres sobrenaturais, a vida de Deus na alma do homem, um mistério. Uma clássica definição desse tipo é do antropólogo Edward Tylor (18321917), que define a religião como a crença em deuses. As definições funcionais buscam estabelecer a utilidade ou os efeitos que a religião tem na sociedade. Um representante clássico é Émile Durkheim, para quem a religião tem a finalidade de manutenção da ordem social por meio da solidariedade, evitando assim a anomia. Nas palavras do próprio Durkheim (2000, 32): "uma religião é um sistema solidário de crenças e de práticas relativas a coisas sagradas, isto é, separadas, proibidas, crenças e práticas que reúnem numa mesma comunidade moral, chamada igreja, todos aqueles que a elas aderem”. Outro expoente da definição funcional é Luckmann, no livro The invisibel religion (1970), que define 
religião como a transcendência da natureza biológica pelo organismo.

Outro grupo de teorias funcionais tem como representante ilustre Sigmund Freud (1978a, 1978b), que concebe a religião como um estratagema criado pelo desejo do ser humano suportar as ansiedades, as decepções da vida e de seu fim último, a morte. A religião é uma projeção inconsciente para superar problemas emocionais que a vida impõe ao ser humano. Nas próprias palavras de Freud (1978a, 107), as ideias religiosas "proclamadas como ensinamentos não constituem precipitados de experiência ou resultados finais de pensamento: são ilusões, realizações dos mais antigos, fortes e prementes desejos da humanidade. O segredo de sua força reside na força desses desejos”. A definição de Freud se assemelha muito às de Ludwig Feurebach e Karl Marx, segundo Alister McGrath e Joanna McGrath (2007). Segundo McGrath e McGrath, esses pensadores têm um pressuposto naturalista na base de sua definição. Deuses não existem (tese do naturalismo), contudo, muitos seres humanos acreditam em Deus. O motivo é a consolação porque elas "projetam" ou "objetivam" seus desejos em Deus ou nos deuses. Como Deus não existe, portanto, a religião é uma projeção humana. $O$ desejo do ser humano pelo divino não é uma necessidade natural, como é a água, mas uma invenção da mente imatura e mesmo doente ou das disfunções sociais.

Existem muitos problemas com as definições substancias e funcionais em termos de uma definição explícita. As definições substanciais ou funcionais têm entre seus defeitos serem amplas ou estreitas demais. Assim, mais coisas seriam ou não religião do que desejaríamos que fossem. Se a definição de Marx de que a religião é o ópio do povo fosse 
correta, então, para alguns, assistir à TV também seria uma religião, algo que poucos aceitariam como uma definição explícita de religião. Se a definição de Tylor de que religião é a crença em deuses fosse adequada, o budismo primitivo não seria religião. Outro problema que vem de um aspecto intrínseco de algumas dessas definições funcionais é que elas são influenciadas por uma teoria antropológica chamada funcionalismo. Uma das críticas antropológicas gerais ao funcionalismo é considerar todas as instituições e práticas sociais como funcionais, porém, isso é falso. As sociedades são por vezes muitíssimo conflitivas. Historicamente, as religiões têm se mostrado fonte de tensões e de rupturas sociais. Portanto, definir religião como mantenedora dos valores ou da ordem social não parece adequado. Não irei aqui indutivamente tomar todas as inumeráveis definições explícitas substantivas ou funcionais dadas de religião até nossos dias e explorar suas deficiências extensionais. $\mathrm{O}$ ônus da prova será deixado aos defensores de tais definições.

Outro tipo de definição funcional oposta à anterior é de Luiz Gonzaga de Carvalho Neto (2010). A religião nasce de necessidades tipicamente cognitivas humanas. Assim como os animais têm sede, os homens têm necessidade de respostas a alguns de seus conceitos fundamentais. Esses conceitos são o de absoluto - algo que não depende de nada; o de justiça/injustiça - algumas coisas são compreendidas como justas e outras como injustas; o de morte - a experiência da finitude da existência das coisas e do próprio eu. $\mathrm{O}$ ser humano, diante desses conceitos, pode ter um interesse cognitivo de buscar a verdade a respeito do absoluto (Deus), da justificação (paraíso, o céu) e de não sofrimento (inferno, Hades). Esses conceitos abrem os indivíduos a uma realidade transcendente, celestial. 
A religião como instituição tem o objetivo de oferecer respostas a esses problemas cognitivos. Do ponto de vista das religiões, o ser humano possui um órgão que pode conectá-lo com o divino e obter resposta às interrogações. Um símbolo muito comum nas religiões é o anel. $\mathrm{O}$ círculo e o engaste são as partes que mantêm o indivíduo ligado ao mundo e a joia é o símbolo desse órgão inato, que pode ser lapidado e possibilitar a experiência com o divino.

A religião oferece ao crente uma doutrina que auxilia a inteligência no plano discursivo. Ela explica o mundo divino e a relação desse mundo com o terrestre. A religião ajuda o crente no senso do divino. É possível a experiência do sagrado ser confusa e muito ligeiramente esquecida. A religião assegura que a experiência não foi uma ilusão. Além da inteligência e do senso do sagrado, a vontade humana deseja a experiência do divino. Os ritos são o meio pelo qual o crente experimenta o divino por meio de símbolos. O rito é a vivência de um símbolo. Não obstante, além de inteligência e vontade, o ser humano é também sentimentos. Os sentimentos são involuntários, mas devem ser orientados para que possam ser caminho para o transcendente, e não obstáculo. O crente não deve fazer o que os sentimentos pedem, mas seguir os mandamentos e as orientações religiosas.

Em suma, a origem da religião e sua função é responder às interrogações cognitivas a respeito do absoluto, da justiça e da morte por meio da união com o absoluto pelo desenvolvimento do órgão inato espiritual. Auxiliar o crente pela doutrina por meio do senso do sagrado (inteligência), pela bondade e beleza do rito à vontade e pelos mandamentos negativos e positivos.

A persuasão da religião é fundamentalmente feita por 
meio de quatro maneiras: a coerência da doutrina, do rito e dos mandamentos; a santidade, seres humanos moralmente superiores; os milagres, eventos miraculosos; e a arte sacra. Essa definição funcional apresenta alguns problemas se a tomarmos como uma definição explícita. Por exemplo, o budismo hinaiana não possui crenças em deidades pessoais. Divindades não teriam uma função. Nas sociedades primitivas a moralidade não está necessariamente vinculada à religião. Além disso, uma concepção genética a respeito da religião sofre as clássicas críticas de ser demasiadamente especulativa e não verificável, como sustenta Tomoko Masuzawa (1989).

O segundo critério para uma definição filosófica de religião é a neutralidade. Uma definição de religião deve ser classificativa, e não avaliativa. Não queremos uma definição que nos diz qual é a boa religião, mas o que é religião independente de seu valor. Algumas definições de religião são nitidamente projeções valorativas de uma determinada religião considerada superior a todas as outras. Por exemplo, Agostinho, Cipriano e Orígenes e o mártir Justino defendiam que as outras religiões não eram a vera religio, mas a ação de demônios (WEBB, 2009). Alguns padres da Igreja viram as religiões pagãs de uma maneira mais simpática, como sementes do Verbo ou prenúncio do cristianismo, como Clemente de Alexandria (150-215), mas quase sempre estavam a elogiar a filosofia, e não as religiões, vistas como inimigas. Algumas outras concepções são projeções etnocêntricas. $\mathrm{O}$ autor define o que é religião por meio de sua religião étnica. Por exemplo, a definição de Rudolf Otto de religião como a experiência do sagrado que enche as pessoas de temor e fascínio é considerada por alguns estudiosos como Klaus Hock (2010) fruto de seu protestantis- 
mo liberal, e essa crítica se estende a muitos outros fenomenólogos da religião. Outros preconceitos etnocêntricos são a religião entendida pelo dualismo de mundo natural e sobrenatural. Muitas religiões indígenas americanas não pressupõem essa dicotomia. Nem sempre a religião se apresenta como uma questão doutrinária ou filosófica. Os hindus, por exemplo, aceitam o hinduísmo porque pertencem a uma casta, e não por uma questão doutrinária. Nem sempre também a religião é definida por uma crença em uma divindade pessoal. O budismo, o taoísmo e o confucionismo não são religiões centradas numa divindade pessoal. No caso do budismo theravada, em divindade alguma. Certamente muitas definições substanciais ou funcionais de religião não são neutras e nem capazes de nos oferecer um conceito adequado de religião.

Outro aspecto de uma definição filosófica de religião é ser fenomenológica. Em Aristóteles, definir é oferecer o gênero próximo e a diferença específica a partir de conceitos que já conhecemos para definir o ainda não conhecido. $O$ gênero próximo e a diferença específica devem ser conceitos já conhecidos, pois se evita uma regressão ao infinito. Isso quer dizer que uma definição de religião deve ser baseada nas propriedades advindas das práticas religiosas, e não em aspectos profundos da história, da sociedade, da psicologia ou da biologia. Uma teoria antropológica que defina religião como antropocentrismo (Guthrie 1993) ou mesmo uma teoria neurológica que defina a religião como um produto do sistema cerebral límbico (Ramachandran 1999) podem até ser boas como teorias científicas, mas não servem como definição filosófica adequada de religião. Uma das razões é que não temos uma teoria geral de religião que seja aceita pela comunidade científica ou pela maioria das 
pessoas. Contudo, antes dos astrofísicos saberem que as estrelas possuíam luz própria por meio de um processo de fusão nuclear, bastou o critério fenomenológico de emitir luz própria. Filosoficamente é interessante um conceito fenomenológico de religião, pois mesmo criticando uma teoria científica sabemos do que estamos falando. Outro exemplo, o antropólogo James M. Donovan (2003), após fazer várias considerações pertinentes sobre os problemas definicionais de religião, acaba ele mesmo defendendo sua própria teoria científica de religião como "todo sistema de crença que serve a função psicológica de aliviar a ansiedade da morte”. Essa definição é claramente não fenomenológica e, portanto, não seria uma boa definição filosófica de religião, além de não ser uma definição que muitos aceitariam como correta. Por exemplo, ela parece estar equivocada a respeito de várias religiões. $\mathrm{O}$ cristianismo, o judaísmo, o islamismo pregam a danação eterna na outra vida pelos pecados não perdoados feitos nesta vida após a morte. Isso não parece nada como uma "função psicológica de aliviar a ansiedade da morte", mas sim aumentar e provocar o medo da morte.

Por fim, o último critério de uma definição filosófica de religião é a não circularidade. Devemos evitar uma definição de religião em termos ou em linguagem religiosa irredutível. Esse critério auxilia a definição não ser circular e a clareza do objeto definido. Alvin Goldman (1979) foi um dos primeiros a chamar a atenção para isso quando alertava para não definirmos justificação utilizando termos epistêmicos, pois não encontraríamos, desse modo, uma definição clara de justificação, assim como definir ética em termos de ter um comportamento bom. Definindo ética em termos éticos (circularidade), temos o problema de definir o que é bom, e assim por diante. Portanto, definir religião como a 
crença em Deus ou deuses, no sagrado, no mistério, não é filosoficamente adequado. É possível que este último critério seja forte o bastante para fazer que seja impossível definir religião filosoficamente. Um exemplo de aparente não circularidade nos é oferecido na definição de religião como sistema cultural do antropólogo Clifford Geertz. Segundo Geertz (2008, 67) religião é: "(1) um sistema de símbolos que atua para (2) estabelecer poderosas, penetrantes e duradouras disposições e motivações nos homens através da (3) formulação de conceitos de uma ordem de existência geral e (4) vestindo essas concepções com tal aura de factualidade que (5) as disposições e motivações parecem singularmente realistas". Contudo, a teoria de Geertz apresenta obscuridades segundo a crítica de Stewart E. Guthrie (2006, 290-291). A definição de Geertz é funcional. A religião motiva, sacia e inspira os crentes apresentando uma cosmovisão ordenada e significativa do mundo, mas não especifica claramente que tipo de significado oferece, exceto para dizer que é um significado "último". Tampouco explica precisamente por que esse significado é convincente. $\mathrm{O}$ termo obscuro é "ordem geral da existência”, que está no centro da definição. Guthrie chama esse conceito de "caixa preta” da definição de religião de Geertz.

Podemos concluir, por enquanto e até onde sabemos, que ninguém ofereceu uma definição explícita de religião que consiga satisfazer os requisitos filosóficos de precisão extensional, neutralidade, fenomenologia e não circularidade.

\section{INDO ALÉM DAS DEFINIÇÕES EXPLÍCITAS}

Existem três possibilidades. Continuar tentando uma defi- 
nição explícita de religião, abandonar o conceito ou compreender o conceito por meio de outro modo além das definições explícitas. Nossa proposta é estabelecer uma definição de religião baseando-nos nas ideias das Investigações filosóficas (1953) de Wittgenstein como foi sustentado, de modo semelhante, por Morris Weitz acerca da definição de arte ou, mais especificamente, de literatura, em seu clássico artigo The role of theory of art (1956).

Até este momento não duvidamos de um pressuposto que mantivemos a respeito da definição de um conceito. Este pressuposto remonta a Sócrates. Quando definimos um conceito pretendemos encontrar um conjunto ou uma propriedade que todos os objetos devem possuir, sejam elas intrínsecas ou extrínsecas ao objeto. É fundamentalmente isso que Wittgenstein critica nas Investigações filosóficas. Não há nada em comum em alguns conceitos, esses conceitos são definidos pelo que Wittgenstein chamou de semelhanças de família. Ele esclarece sua ideia contra o essencialismo das definições com o exemplo do conceito alemão de Spiel (jogo, brincadeira). Segundo o filósofo austríaco, não há nada em comum a todos os jogos, não obstante, as semelhanças que os jogos partilham entre si fazem que usemos a palavra jogo para toda a imensa variedade de jogos. Existem apenas semelhanças, mas não uma propriedade idêntica comum a todos os jogos.

Weitz utilizou essas ideias wittgensteinianas para definir arte e literatura. Para Weitz, conceitos como "arte", "literatura" e outros são de "textura aberta". Conceitos passíveis de modificações, dada a criatividade artística e as novas artes que vão sendo constantemente elaboradas. Tais conceitos de textura aberta só podem ser definidos por meio de suas semelhanças. Porém, há conceitos de "textura fecha- 
da", como "tragédia grega", que podem ter uma definição explícita. Primeiro porque temos propriedades necessárias e suficientes, em segundo, por ser um conceito morto, pois não há mais artistas criando novas tragédias gregas. De modo análogo, podemos definir religião por meio de suas semelhanças. Religião é um conceito aberto, novas religiões estão surgindo e muitas igualmente desaparecendo.

Um exemplo de uma lista de características de religião definida por semelhança de família foi dado por William Alston (2006). Ele elenca nove propriedades para uma caracterização de religião: a crença em seres sobrenaturais (Deus ou deuses); a distinção entre o sacro e o profano; atos rituais focados sob objetos sagrados; um código moral sancionado por Deus ou pelos deuses; sentimentos religiosos (senso do mistério, adoração, assombro, fascínio); oração e outros tipos de comunicação com o divino; uma visão geral da vida e da morte, uma organização mais ou menos total da existência (cosmovisão); por fim, um vínculo com uma comunidade religiosa. Assim, não podemos dizer se algo é ou não religião. As fronteiras do que é ou não religião são nebulosas, vagas. Rigorosamente, podemos apenas dizer se algo é mais ou menos religião, a saber, se tem mais ou menos semelhanças com o conjunto de características de religião. Em suma, não temos uma definição de religião, temos apenas uma caracterização de religião ou um conceito brando de religião.

Além disso, William Alston oferece outro modo de caracterizar a religião, trocando a pergunta sobre a essência da religião pelo lugar da religião, semelhante a Nelson Goodman, que trocou a questão da essência da arte pela pergunta quando há arte. Podemos agrupar as religiões em três grupos, nos quais o divino é encontrado: nas religiões sa- 
cramentais, nas proféticas e nas místicas. Claro que esses lugares do divino podem estar misturados em algumas religiões ou serem valorizados de modos diversos. Nas religiões sacramentais o divino é achado fundamentalmente nas coisas, nos objetos, nas relíquias, nos alimentos, nas coisas vivas e mesmo nos processos como a dança. Isso não quer dizer que essas coisas são divinas. Quando isso acontece dáse o nome de fetichismo. As coisas são a habitação ou a manifestação do divino. $\mathrm{O}$ rito é muito importante nesse tipo de religião, ele ocupa um lugar central. A doutrina e a experiência do crente não são muito importantes. As religiões mais primitivas são fundamentalmente sacramentais. Por exemplo, a Arca da Aliança, o Ganges e a Eucaristia. Um exemplo desse tipo é o hinduísmo. Nas religiões proféticas, Deus se manifesta na história humana. $\mathrm{O}$ modo de revelação da divindade é majoritariamente pela palavra. Deus se encontra na natureza, mas de uma forma privilegiada nas mensagens dos profetas e textos sagrados. As religiões proféticas são fundamentalmente a aceitação das leis divinas. A fé ocupa o lugar do ritual, uma fé que deve se expressar na ação do crente. $\mathrm{O}$ acento é no cumprimento dos mandamentos divinos. Exemplos desse tipo de religião são o judaísmo, o cristianismo, o islamismo, o confucionismo. Nas religiões místicas, a experiência mística ou interior é o lugar do encontro do divino. $\mathrm{O}$ místico sente-se transformado pelo divino. A prática de uma vida ascética e de contemplação leva o místico à transformação e à experiência religiosa. As religiões místicas não dão muito acento para a doutrina. A doutrina sempre é uma deturpação da experiência. Nunca expressa perfeitamente o divino. Porém, alguns símbolos são melhores que outros - por exemplo, o budismo e o hinduísmo filosófico. 
Voltando ao problema de definir por meio das semelhanças de família, claro que houve objeções a Weitz ao utilizar as ideias de Wittgenstein no âmbito das artes. Contudo, algumas críticas feitas a ele em relação à arte podem ser evitadas no âmbito do conceito de religião. Nigel Warburton, em seu livro O que é arte? (2003), faz as seguintes críticas: primeira, quem é o "nós" que diz que algo é ou não arte ou um romance? Segunda, tudo pode de alguma forma ter semelhança com tudo, como podemos saber quais dessas semelhanças são relevantes? Como estabelecer a existência da primeira arte, se não havia nada para ser comparado? Mutatis mutandis, podemos transferir essas mesmas críticas ao conceito de religião. Quem é o "nós" que define ou não algo como religião? São fundamentalmente os estudiosos, os acadêmicos ocidentais de religião, conforme nós víamos no início deste texto. $\mathrm{O}$ conceito de religião é uma invenção cultural da modernidade e dos estudiosos de religião; é uma invenção social, um construto, uma abstração, não uma espécie natural. Semelhantes críticas foram feitas aos conceitos de arte e de moda. Existem vários tipos de argumento para sustentar essa tese, sejam filológicos ou históricos. A religião não é uma espécie ou categoria, como é um leão ou o ouro. Como sabemos quais são as características relevantes de religião? Quando definimos religião por suas semelhanças utilizamos um protótipo (SALER, 2000), feito a partir das religiões que nós ocidentais conhecíamos, ou seja, o cristianismo, o judaísmo e, um pouco menos, o islamismo. É difícil conhecermos algo se não conseguirmos estabelecer semelhanças com algo já conhecido. No caso de uma religião, conhecemos outra religião a partir daquilo que conhecemos da própria religião. É muito difícil alguém que nunca participou de religião com- 
preender o que é. Existe um etnocentrismo congênito, mas que pode ser aos poucos transcendido. Parece não haver uma impossibilidade de tradução inter-religiosa completa. Por exemplo, nosso protótipo de pássaro nos diz que um pombo é mais semelhante a outros pássaros do que um pinguim. Agora, se no mundo começássemos a perceber que existissem mais pássaros parecidos com o pinguim, no fim de uma vasta experiência diríamos que o pombo é menos semelhante a um pássaro do que pinguim. Por fim, como estabelecemos a primeira religião, se não havia nada para comparar? Como já vimos nas respostas anteriores, usamos nossa religião para comparar com as outras e assim formar uma semelhança de família. Nascemos em uma religião, ou num domínio cultural religioso ou pelo menos num resto cultural religioso. Historicamente, o Ocidente foi formado pela influência do cristianismo e do judaísmo e, naturalmente, comparamos nossa tradição religiosa com outras tradições a partir desta, que já estava estabelecida. De fato, se muitas vezes olhamos principalmente as diferenças entre as religiões, saltam aos olhos as muitas semelhanças.

\section{CONSIDERAÇÕES FINAIS}

Em suma, não podemos ter uma definição filosófica explícita de religião pelos critérios razoáveis de precisão extensional, neutralidade, fenomenologia e não circularidade que assumimos. Todavia, não precisamos assumir que uma definição tem que apenas fornecer condições necessárias e suficientes e que cumpram os critérios estabelecidos por Webb (2009). Mesmo que longe de uma definição desejável, podemos elaborar uma caracterização de religião baseados nas ideias wittgensteinianas de semelhança de família e 
isso não impede que o conceito seja definido de outras formas e com outros recursos técnicos como os tipos ideais de Max Weber. Por sua vez, essa caracterização ou definição branda não enfrenta os problemas apontados por Warburton à definição de literatura proposta por Weitz. Além disso, podemos manter o conceito de religião, mesmo aceitando que a origem do conceito é uma invenção acadêmica de aglutinar certas práticas culturais semelhantes sob o conceito de religião. Portanto, a definição por semelhança de família estaria refletindo em si mesma a origem de tal conceito.

Abstract: this article aims to analyze the problems of defining and classifying explicitly the concept of religion. We agree with the criteria of extensional accuracy, neutrality, phenomenology and non-circularity established by Mark Owen Webb (2009) as suitable for a good philosophical definition of religion. However, all attempts to establish an explicit definition that satisfies these criteria were unsuccessful. We propose a definition of religion less demanding, sustained by Morris Weitz (1956) for literature and applied mutatis mutandis to the concept of religion. Also, the definition can be refined by the prototypical theory as developed by Benson Saler (2000).

Keywords: definition; religion; concept.

\section{REFERÊNCIAS}

ALSTON, William. Religion. In: BROCHET, Donald. Encyclopedia of philosophy. Darke: Tompson Gale, 2006. p. 366-373.

CARVALHO NETO, Luiz Gonzaga de. O que é religião? Disponível em: http://luizgonzagadecarvalho.com/. Acesso em: 20 out. 2010.

DONAVAN, James. Defining religion. In: GLAZIER, Stephen D.; FLOWERDAY, Charles A. Selected readings in the anthropology of religion: theoretical and methodological es- 
says. Westport, Conn.: Praeger, 2003. p. 61-98.

DURKHEIM, Émile. As formas elementares da vida religiosa: o sistema totêmico da Austrália. São Paulo: Martins Fontes, 2000.

Fitzgerald, Timothy. The ideology and religious studies. New York: Oxford University Press, 2003.

Freud, S. O futuro de uma Ilusão. In: Os pensadores: Vol. Freud. Trad. de D. Marcondes et al. São Paulo: Abril Cultural, 1978a. p. 87-128.

. O mal-estar na civilização. In: Os pensadores: Vol. Freud. Trad. de D. Marcondes et al. São Paulo: Abril Cultural, 1978b. p. 131-194.

GEERTZ, Clifford. A interpretação das culturas. Rio de Janeiro: LCT, 2008.

GOLDMAN, Alvin. O que é crença justificada? 1979. Disponível em: http://criticanarede.com/justificacao.html. Acesso em: 15 out. 2012.

Guthrie, Stewart E. Faces in the clouds: a new theory of religion. New York: Oxford University Press, 1993.

Anthropological theories of religion. In: MARTIN, Michael. Cambridge companion to atheism. Cambridge: Cambridge University Press, 2006. p. 283-299.

HEGENBERG, Leonidas. Definições: termos teóricos e significado. São Paulo: Cultrix, 1974.

HOCK, Klaus. Introdução à ciência da religião. São Paulo: Loyola, 2010. 
LUCKMANN, Thomas. The invisible religion: the problem of religion in modern society. New York: The MacMillan Company, 1970.

MASUZAWA, Tomoko. The invention of world religion. London: Chicago University Press, 2005.

. In search of dreamtime: the quest for the origin of religion. London: Chicago University Press, 1989.

McGRATH, Alister; McGRATH, Joanna. O delírio de Dawkins: uma resposta ao fundamentalismo ateísta de Richard Dawkins. São Paulo: Mundo Cristão, 2007.

MURCHO, Desiderio. Definição. In: BRANQUINHO, João et al. Enciclopédia de termos lógico-filosóficos. São Paulo: Martins Fontes, 2006. p. 239-41.

Ramachandran, v. s. et al. Phantoms in the brain: probing the mysteries of the human mind. New York: William Marrow Paperbacks, 1999.

SALER, Benson. Conceptualizing religion: immanent anthropologists, transcendent natives, and unbounded categories. New York: Berghahn Books, 2000.

STARK, Rodney; BAINBRIDGE, William Sims. Uma teoria da religião. São Paulo: Paulinas, 2008.

SMITH, Jonathan Z. Imagining religion: from Babylon to Jonestown. London: University of Chicago Press, 1988.

SMITH, C. Wilfred. The meaning and end of religion. New York: A mentor book, 1964.

WARBURTON, Nagel. O que é a arte? Lisboa: Bizâncio, 
2007.

WEBB, Mark Owen. An eliminativist theory of religion. Sophia, v. 48, p. 35-42, 2009.

WEITZ, Morris. The role of theory of art. Journal of aesthetics and art criticism, v. 15, p. 27-35, 1956.

WITTGENSTEIN, Ludwig. Investigações filosóficas. Lisboa: Fund. Calouste Gulbenkian, 1953/1987.

ZAGZESBSKI, Linda. O que é conhecimento? In: SOSA, Ernest; GRECO, John. Compêndio de epistemologia. São Paulo: Loyola, 2008. p. 153-189. 